\title{
The Salman Rushdie Archive and the Re-Imagining of a Philological E-volution
}

\author{
Benjamin Alexander
}

"Our writing tools are also working on our thoughts,"

FREDERICK NIETZSCHE, TYPEWRITTEN MANUSCRIPT

The following discussion is shaped by a particular historiographic sensitivity that combines a perspective on the archive as an intellectual body that facilitates complex scholarly practices of remembering, forgetting, and re-remembering, with a parallel concern for evolving processes of intellectual exchange involving the archive and the literary scholar. At the centre of this discussion rests the Salman Rushdie Archive, a collection of personal materials that, from the point of view of both the archive and the literary scholar, is radical in both its form and content.

My particular engagement with the Salman Rushdie Archive introduces (and then offers to reconcile) two distinct observations. First, The Salman Rushdie Archive is among the first collections to provide a scholarly perspective on the increasingly intricate practice of twenty-first century textual inquiry that is, at present, being shaped and reshaped by scholars' access to an archival record that increasingly includes authors' engagements with both material evidence and complex digital matrices. Second, dating from the $1990 \mathrm{~s}$ (approximately the years in which Rushdie prepared and transferred his materials to the care of the archive), some literary scholars began to engage in what they called New Philology and to apply its strategies to the interpretation and re-interpretation of texts. Basing themselves on the work of Bernard Cerquiglini (1989), they argued for the study of texts in all its variations from a broad spectrum of literary, historical and critical discourses. ${ }^{1}$ When sensitively configured, these lines of discussion coalesce around a broadening critical perspective regarding the subjective nature of the manufacture of texts

1 Esp. Nichols (1990) and Wenzel (1990).

(C) BENJAMIN ALEXANDER, 2015 | DOI 10.1163/9789004270848_006

This is an open access chapter distributed under the terms of the Creative Commons AttributionNoncommercial 3.o Unported (CC-BY-NC 3.0) License. 
(manuscript, printed and digital); and, which recalls Bernard Cerquiglini's observation that, "medieval writing does not produce variants; it is variance."

The Rushdie Archive is among the first archival collections to document the evolution of the intellectual and imaginative practices of a twentieth and twenty-first century author as they progressed from a combined reliance on material inscription and typewriting technologies, to, at present, an almost exclusive dependence on the fluidity of digital composition. Most succinctly, the Salman Rushdie Archive is revolutionary (I use this term with extreme caution); and, it is revolutionary from a combination of intellectual and historical perspectives that reach deep within the archive and across a breadth of academic and historical interests. ${ }^{3}$

\section{Salman Rushdie and the Archive: Shaping Twenty-first Century Literary Memory}

On March 15, 2010 The New York Times published an article entitled Fending Off Digital Decay, Bit by Bit. "Among the archival material from Salman Rushdie currently on display at Emory University in Atlanta are inked book covers, handwritten journals and four Apple computers (one ruined by a spilled Coke)" the article begins. "The 18 gigabytes of data they contain seemed to promise future biographers and literary scholars a digital wonderland: comprehensive, organized and searchable files, quickly accessible with a few clicks."

With the opening of "Sir Salman Rushdie's archive," visitors to the web portal for Emory's Manuscript, Archives, and Rare Book Library, observe, "the celebrated writer's computer files, private journals, notebooks, photographs and manuscripts that provide insight into his creative process, campaigns for human rights and celebrity." "The multimedia exhibit, $A$ World Mapped by Stories," the web-page further notes, "also marked a significant step forward in the preservation of personal digital materials." 5

2 Cerquiglini (1989), quoted in Nichols (1990) 1.

3 Like many things archival, it is worth noting the historical fortune that explains the preservation of Rushdie's original computing devices. During a recent interview posted to Emory's webpage, Rushdie explained to curator Erika Farr that during the fatwa, he avoided discarding his computers out of concern for his personal safety. Instead of throwing them away he simply kept them in a closet until their eventual transfer to the archive.

4 Cohen, Patricia, "Fending off Digital Decay, Bit by Bit," in New York Times 15 March 2010.

5 Elaine Justice, A World Mapped by Stories: The Salman Rushdie Archives. Emory University, Robert Wood W. Woodruff Library. Web.library.emory.edu. 
A brief review of catalogue record (Finding Aid in archival parlance) to the Rushdie Archive immediately points to its groundbreaking contribution both to the archive generally and by Emory's archivists specifically. It follows that the Finding Aid itself identifies ways in which the twenty-first century archivist will play an increasingly visible role in the shaping of literary scholarship. "The papers include journals, appointment books, and notebooks; writings by Rushdie, specifically manuscripts and typescripts of his fiction, nonfiction, scripts and other writings," the finding aid begins. The guide then departs from the familiarities of material matrices and introduces points of access to the gestation of twenty-first century literatures within the expanding fluidity of digital technologies.

Of particulate note in the collection is the digital material from four of Rushdie's computers in addition to a hard drive. The files currently available to researchers are from one of his earlier computers, a Macintosh Performa 5400; they date from 1992-2002, and consist of notes and drafts of Rushdie's writings and selected correspondence. Of particular interest is a small cache of email correspondence, representing Rushdie's first foray into this emerging form of communication in the late $1990 .^{6}$

What is truly revolutionary about the Salman Rushdie Archive is the convergence of scholarly opportunity to explore both the evolution of Rushdie's creativity within the specific material spaces (hardware), and, the evolving digital matrices (software) that the author preferred across the first decades of the personal computer revolution.

"At the Emory exhibition," observes Erika Farr, Director of Born Digital Archives at Emory, "visitors can log onto a computer and see the screen that Mr. Rushdie saw, search his file folders as he did, and find out what applications he used. They can call up an early draft of Mr. Rushdie's 1999 novel, The Ground Beneath Her Feet, and edit a sentence or post an editorial comment."7 "To the Emory team," Farr further observes, "simulating the author's electronic universe is equivalent to making a reproduction of the desk, chair, fountain pen and paper that, say, Charles Dickens used, and then allowing visitors to sit and

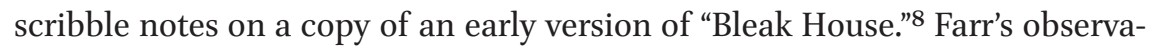

6 Rushdie, Salman, Salman Rushdie papers, 1947-2008. Emory University, Manuscript, Archives, and Rare Book Library.

7 Elaine Justice, A World Mapped by Stories: The Salman Rushdie Archives. Emory University, Robert Wood W. Woodruff Library. Web.library.emory.edu.

8 Ibid. 
tions point directly to the fundamental observation of this essay: namely that the introduction of multifaceted combinations of material and digital evidences into contemporary literary archives is concurrent with the emergence of new developments in textual scholarship which seek to apply New Philology to the interpretation of texts across increasingly broad fields of study.

At present, researchers can interact with Rushdie's digital tools from the relative origin of the commercialization of the personal computer through to the present. One of the great challenges of the digital age remains, of course, the fact that the technologies of composition will continue to shape and reshape authors' creative processes at a pace that obscures our judgment of the relative primitivism of machines produced only a year or two ago. So too such technologies of composition will remain in advance of the commensurate technologies which are capable of preserving and providing access to outdated hardware and software. The Rushdie Archive retards such distortions and allows scholars to sensitively consider the production of literature according to limited spaces and operating capabilities of the word processing technologies dating from the mid-1980s.

Farr notes specifically scholars' access to both the actual hardware Rushdie engaged with and the ability to: "search his file folders as he did, and find out what applications he used (Mac Stickies were a favorite)."9 Such remarkable access illuminates the tremendous broadening of potential capture and preservation of literary "memory" that digital technologies offer first to the archive, and then to the scholar. Such access provides a kind of simulation of experience (that is, opportunities for research within an expanding context of creation) that are unimaginable within the comparatively limited matrices of manuscripts and printed texts. While scholars' engagement with Rushdie's primary materials will always take place within the context of the archive (a privileged cultural space distanced from the author's environment of composition), the archive creates an additional layer of context to the gestation of particular texts that is truly revolutionary, by providing access to both Rushdie's computers and their operating systems.

Further, and of particular importance to the study at hand, Emory's contribution to both the expanding perspectives of the archive and concurrent evolutions of textual and literary scholarship portends additional points of entry into textual analysis. To-date, archivists have provided access to the digital manuscripts and drafts of manuscripts that Rushdie, himself, saved; i.e. to those files that are representative of Rushdie's creative process. These "digital 
manuscripts" are emphatically distinct from the additional layers (I use this word literally) of evidence that remain imprinted on the author's hard-drives. This is an essential distinction. While access to the former is unquestionably profound, the opportunity to access the latter will be truly revolutionary. And, I argue, it is a shared awareness among academics of this emerging potential to access latent and discarded evidences that helps to explain the on-going revaluations among textual scholars from the early modern period through to the present.

Emory, however, is not alone its efforts to capture and provide access to our twenty-first century literary heritage. The Harry Ransom Center is working to make available digital records contained within the Norman Mailer Papers. ${ }^{10}$ Mailer, a contemporary of Rushdie's, shared his experience of transitioning from manuscript to digital writing practices. Moreover, the Ransom Center can make the persuasive claim that it contains (perhaps maintains) the archival record that gives context to the first comprehensive evidence of hypertext fiction: Michael Joyce's Afternoon: A Story.

The commitment of institutions like Emory to preserving the evolution of the twenty-first century imagination as it continues to interact with digital technologies is historically unprecedented. If institutions like Emory University and the Ransom Center were more limited in their perceptions of textual scholarship they could easily migrate the digital evidences contained on the hard-drives of authors like Rushdie and Mailer and, much to their financial benefit, disregard the responsibility for maintaining the operation of authors' computers.

\section{Reimagining the Text}

During the precise years that Rushdie was negotiating for the transfer of his archive to Emory, and during which time archivists at Emory were making revolutionary forays into the preservation and access to digital evidences, literary scholars began to ask some fundamentally New Philological questions about the very nature of texts dating from the early modern period through to the relative present. The reasons for this concurrent shift or, perhaps, advancement in archival practices and literary scholarship are, I believe, easily explained. Dating from the early 1990s, textual and literary scholars generally

10 For additional information about the Norman Mailer Papers, see Norman Mailer: An Inventory of His Papers at the Harry Ransom Center available at http://www.hrc.utexas. edu/. 
began to appreciate the coming challenges that digital technologies introduced. Indeed, dating from this period there was a reorientation in scholarly perspective on the very nature of primary evidences, and their process of production, preservation, and future access, that remains rooted in scholars' various engagements with the complexities of digital technologies - that is, their personal experiences of the "computer revolution." Hindsight reveals a remarkable parallel energy occurring both within the archive itself, and, across the field of literary scholarship more generally. The opening of the Salman Rushdie Archive simply brings into focus these parallel interests, and illustrates their increasing convergence and process of mutual exchange.

At the very centre of these convergent energies rests a fundamental engagement with New Philology as it was envisioned by scholars dating from the early 1990s. "A rethinking of philology should seek to minimize the isolation between medieval studies and other contemporary movements in cognitive methodologies, such as linguistics, anthropology, modern history, cultural studies, and so on," Stephen Nichols observes in the introduction to The New Philology, "by reminding us that philology was once among the most theoretically avant-garde disciplines."11 "In its wider sense philology serves the basic urge to understand a work of verbal and usually written communication," writes Siegfried Wenzel in the same text. "But," Wenzel continues,

in doing so it goes beyond the strict concentration on language and its aspects, to include whatever contextual information might help to elucidate a text: first of all its sources, but then also political and other aspects of history, biography where the writer is known, socioeconomic conditions (such as patronage or practical demand for books), the conditions and processes of writing or copying a document and of printing, the religion or Weltanschauung of the culture from which the text comes, the intended use of the text (its Sitz im Leben, to use the fashionable phrase), and much else. ${ }^{12}$

To align critical observations regarding the evolution of textual scholarship across the past two decades with the introduction of digital evidences into the archive is to observe a kind of fruition of the critical observations offered by New Philologists including Nichols and Wenzel.

In my view scholars like Adrian Johns, David Kastan and Franco Moretti have both incorporated and expanded upon the New Philologists' concern for

\footnotetext{
$11 \quad$ Nichols (1990) 1.

12 Wenzel (1990) 12.
} 
contextual study in order to explain the formation of literary conventions dating from the English Renaissance through to the Victorian age. Other scholars, I am thinking of Lawrence Rainey specifically, have pioneered a philological approach to the interpretation of twentieth century texts; indeed, texts which had long assumed to have exhausted the research value of their primary sources. Most recently, Matthew Kirschenbaum in particular has turned his attention to the exploration of the revolutionary advances in writing tools that have reshaped creative practices across the past half-century, exploring, in Kirschenbaum's words, the twenty-first century "forensic imagination."13

This is a tremendous breadth of recent scholarship that has coalesced around what are fundamentally new philological discourses and which has been simultaneously facilitated by scholars' engagement with digital technologies.

The question, of course, is why did these seemingly distinct interests emerge from both within the archive and the academy during this concurrent period in time? The answer, I believe, is in the ways that digital technologies have encouraged new ways of viewing our literary and cultural heritage.

\section{The Text Re-Imaged}

It is a case best made through example. On October 29th 1998, Christies Auction House auctioned an extraordinary volume. The text, a thirteenth century prayer book composed in Constantinople, was purchased by an anonymous collector who immediately placed the volume in the care of curators and conservators at the Walters Art Museum in Baltimore, Maryland. What makes the volume so extraordinary is that it is, by every definition, a palimpsest. ${ }^{14}$ In itself this may not seem remarkable. Once in the care of conservators at the Walters, however, a fascinating combination of intellectual and technological energies converged on this volume. In fact, the particular nexus of these technological and interpretative practices identify the Archimedes Palimpsest as a defining moment in anticipating how cultural heritage materials and manifestations of "memory" in general will be accessed and re-imagined in twenty-first century contexts.

The Archimedes Palimpsest, as this volume has come to be known, is one of only three manuscripts that are known to have contained seminal philosophical and physical observations attributed to Archimedes written in ancient

13 Kirschenbaum (2008).

$14 \quad$ Netz and Noel (2007). 
Greek, the language of the philosopher. The text includes two of Archimedes' treatises that can be found nowhere else: The Method and Stomachion. Two other volumes that are believed to have contained comparable traces of Archimedes' treatises disappeared in ca. 1311 and 1550 , respectively. The only other comparable volume that contains evidences of Archimedes' ideas dates from approximately $700 \mathrm{CE}$ (400 years before the production of the present text).

What makes this volume so singularly remarkable, however, is that it remains, in its very nature, a palimpsest. The present volume comprises 174 folio pages inscribed on parchment. Collectively, however, these pages represent a physical and intellectual synthesis of leaves that were excised (literally extracted) from at least five distinct pre-existing texts, including: ten pages of writings attributed to Hyperides; six folio pages of an unidentified Neoplatonic text; four folio pages from an unknown liturgical manuscript; and a further twelve pages from two texts that have not yet been identified.

The monks working in Constantinople during the twelfth century and who intended the composition of a prayer book identified for the materials of their volume leaves from these disparate texts. ${ }^{15}$ They then scraped the extant inks from their pages and resized the leaves to fit the uniform dimensions of their intended volume, and then initiated their process of composition. From the point of view of the archive, what the twelfth century monks pursued during their production of a Euchologion was in fact a complex process of removing previous attempts to converge thought (culture in its immaterial form) with its material representation, that is - in the case of the Archimedes Palimpsest leaves of text, from their existing or pre-intended intellectual and physical contexts (again, leaves of text). They then reconfigured their intellectual and physical properties to fit their own particular set of intellectual and cultural interests. From our post-modern archival perspective the Archimedes Palimpsest reveals a fascinating and literal process of remembering, forgetting, and re-remembering.

Once in the care of conservators at the Walters Art Museum, a fascinating confluence of scholarly and technological energies converged upon this remarkable document. After the volume was dis-bound (a process that took close to 4 years), the individual pages were digitally imaged using a process called multispectral imaging. The process allows for the layers of text to be differentiated and discerned. The entire process is a kind of textual archaeology. Layers of textual history have in fact been lifted from the vellum with the

15 Technically the volume the monks composed is known as a Euchologion; a liturgical text of the Eastern Catholic Church corresponding roughly to a Roman Catholic Missal, Ritual and Pontifical. 
result that scholars have had the opportunity to transcribe the Archimedes treatise.

I offer the example of The Archimedes Palimpsest as a segue into a more general philological study precisely because its various interpretations rely upon a convergence of critical interests including a technical concern for how this eleventh century text is being re-imagined within complex twenty-first century digital matrices into which the "original" palimpsest has been repeatedly migrated. In fact, this determinative re-exploration of our cultural and intellectual heritage provides an essential context to the understanding of how philological practices are, at present, being most sensitively explored in twenty-first century digital environments. At the same time, it explains why these same discourses have been effectively re-imagined within an increasing breadth of textual environments.

The exploration of palimpsests is, of course, not new to classical and medieval scholarship. What is perhaps most remarkable about the Archimedes Palimpsest is the kind of scholarly frenzy it seems to have produced. There are, as explained above, clear reasons for the emergence of these critical interests. Most succinctly, a hard-drive, by the very definition of its design and operation, is a palimpsest. And, it is a palimpsest that at present (like its Byzantine antecedent) remains in advance of commensurate technologies that allow for its full analysis. While the archivists at Emory have done a tremendous job in making select digital files accessible, namely those files that the author himself "saved," they have only scratched the surface of an unimaginable wealth of latent evidences that remain encoded on Rushdie's various hard-drives.

To trace the lineage of this scholarly perspective is to observe that from the early 1990s textual scholars began to absorb the palimpsestual complexities of digital culture and intuitively to grasp the potential for new scholarly explorations. However, in the place of a technologically sophisticated "de"-composition of the intellectual contents of a hard-drive which began in approximately 1990, scholars turned their attention towards exploring contexts of creation and the reimagining of established philological discourses within textual spaces dating from the early modern period through to the present. ${ }^{16}$ From my point of view, this is a critical process that traces its roots through the thinking of scholars like Stephen Nichols who, dating from this same period, remained

16 As a point of beginning, I would offer George Bornstein's 1993 text, entitled, simply, Palimpsest. A text that portends, I believe, a subsequent decade's worth of scholarship, and a text that in both title and subject would have been unimaginable during the decade that preceded its publication. 
focused on the "way in which the beliefs of the Middle Ages shaped its institutions and textual artifacts." 17

\section{The Advance of New Philology}

Early forays into the interrogation of twenty-first century texts yields a remarkable synergy of intellectual and technical challenges. Take for example Michael Joyce's novel, Afternoon. Joyce's text was (and still is) published by Eastgate, which as posted on its web portal, remains according to Robert Coover of The New York Times Book Review: "the primary source for serious hypertext."18 The text itself poses endless points of critical revaluation about the very nature of the "text" in the digital age: "I am currently running my Afternoon on a Windows machine, and the work was originally developed and released for the Apple Macintosh," writes Matthew Kirschenbaum,

in its own catalogue Eastgate discriminates between so-called Macintosh and Windows "editions," when what they really mean is that Afternoon has been ported between the two platforms, probably more than once. Selections from Afternoon have also appeared in print, in the Norton Anthology of Post-Modern Fiction (1997), and subsequently online at Norton's Web site, which deploys an elaborate Java-based interface to approximate some of the special features of the original Storyspace software. This on-line version (and port) is identified as the sixth edition of the work by its own colophon, which is otherwise identical to the one I have reproduced above. There are at least two foreign language translations of Afternoon, Italian and German. None of this considers the possibility that copies of Afternoon have been individually altered by their owners and put into circulation, intentionally or otherwise. ${ }^{19}$

All this, Kirschenbaum notes, is external to the additional complexities of interpreting the author's creative process as it migrated among various computers and operating systems. "The Truth is," Kirschenbaum notes, "there are many Afternoons, even if the literary textual differences between them may provide slight; and indeed it is Joyce's own personal habit, when naming folders and

\footnotetext{
17 Nichols (1990) 3 .

18 http://www.eastgate.com/.

19 Kirschenbaum (2008) 261.
} 
subfolders to store backup copies of the work on his personal file systems, to use the plural locution, 'Afternoons."'20

Amid this seemingly overwhelming fluidity of emendation and re-imagining of any text across any number of digital spaces, scholars might feel as if they faced some Sisyphean challenge in trying to establish a socio-historical context that can provide a basis for the interpretation of twenty-first century texts. In fact, I would argue that there are, at present, projects that rival, or perhaps even surpass in terms of their technological sophistication, the context of creation of works like Joyce's Afternoon. Most emphatically I would point to the commitment of the Library Congress to preserve Twitter. "Library officials explained the agreement as another step in the library's embrace of digital media" The New York Times reported in April of 2010. "Twitter, the Silicon Valley start-up, declared it 'very exciting that tweets are becoming part of history."'21 I would also offer the Library of Congress' Web Capture Project as well as Brewster Kahle's monumental project, The Internet Archive. ${ }^{22}$ If successful, the combination of these projects offer the prospect of a socio-historical context unimaginable to scholars of medieval and early modern culture where, in general, the challenge is how to best account for absence rather than face the prospect of overwhelming evidence.

To return to the example of Joyce's Afternoon, with each succeeding observation about the complex lineage of Joyce's work that Kirschenbaum notes, from the point of view of both the archive and the scholar the interpretive challenges increase exponentially to the point where one finds oneself at a kind of critical full-circle, recalling Bernard Cerquiglini's observation regarding "varience" and the nature of medieval culture.

The synergies between such philological discourses and the evolution of twenty-first century critical paradigms do not end with Cerquiglini. "By its origins, in [Erich] Auerbach's view," Nichols writes, "philology represented a technological scholarship made possible by a print culture. It joined forces with the mechanical press in a movement away from the multiplicity and variance of a manuscript culture, thereby rejecting, at the same time, the representation of the past which went along with medieval manuscript culture: adaptation or translatio, the continual rewriting of past works in a variety of versions, a practice which made the copying of medieval works an adventure in supplementation rather than faithful imitation." ${ }^{23}$ Though I doubt he imagined a connection

\footnotetext{
20 Ibid.

21 Lohr, Steve, "Library of Congress will Save Tweets," New York Times April 14, 2010.

22 See http://www.loc.gov/webarchiving/ and http://archive.org/.

23 Nichols (1990) 3.
} 
while he was writing his critique of Auerbach upon some well antiquated word processing machine, Nichols articulates a set of assumptions regarding the nature of print culture and its naively assumed "enhanced fidelity" (to use Adrian Johns' phrase ${ }^{24}$ ) compared with the established subjectivities of the medieval manuscript.

As these conceptualizations of the complex lineage of texts evolved within certain critical circles they have lent to a more general questioning of cultural "memory." The term is broad, but articulates an evolving concern for the problematic relationship between scholars' interrogation of material (historical) artifacts and the inherent subjects of their intellectual composition. "Psychologists know that memory is never a perfect witness to the event remembered," David Kastan observes in Shakespeare and the Book, "it represses, displaces, and falsifies; nonetheless it is informative, though less as an objective representation of the event than as the over determined register of the event's reception and assimilation. Print remembers similarly; it too falsifies even as it recalls and records, incorporating elements separate from that which it would overtly remember. The Shakespeare remembered in the printing house is inevitably something other than Shakespeare - both more and less than his original presence. His corpus is reconstructed by sets of motivations and practices that leave their marks upon the text, distorting it even as they preserve and set it forth." 25

Across the pages of Shakespeare and the Book Kastan peels away layer after layer of assumptions that are, and perhaps were, deeply rooted in a shared cultural confidence about Shakespeare's very presence in the various printed texts that we had long assumed were faithful to some imagined "true original copies." Once exposed, Kastan fills the intellectual space left by these assumed confidences with a collection of subjectivities that shake the very foundation of our assumptions about Shakespeare, and, by close extension, the transmission of his genius across time and space.

As I have been arguing throughout this book, he [Shakespeare] has never really been in any of those textual spaces where we pretend he resides. Nonetheless, we endow each of them with his name, discovering in the various forms of their materiality imagined signs of his presence. We are a bit like Hamlet, looking at a ghost that according to everything he has been taught cannot be his father's spirit. It stands before him in "questionable shape," yet nonetheless the Prince decides to recognize in the

\footnotetext{
24 Johns (1998) 8.

25 Kastan (2001) 15.
} 
apparition an authenticity his Wittenberg education, anyhow, should tell him is impossible: "I'll call thee Hamlet, / King, father, royal Dane" (1.4.445). Looking at the various questionable shapes in which the plays appear to us, we too are motivated (and like Hamlet, more by desire than by knowledge) to find behind the "solid" or "sallied" texts, displayed in whatever media in which we encounter them, a ghostly presence that we call Shakespeare. $^{26}$

Such concern for the subjectivities of the early modern print shop remains at the centre of Adrian Johns' seminal text, The Nature of the Book. "Early modern printing was not joined by any obvious or necessary bond to enhanced fidelity, reliability, and truth," before adding, emphatically: "That bond had to be forged." 27

Johns goes on to observe that, "the publication of any text marks the completion of one set of complex social and technological practices and the beginning of another." ${ }^{28}$ While the observations of both Johns and Kastan are fundamentally philological in their sensitivities, it is essential to note that, despite the exhaustive critical interest in early modern culture, such insights were not fully articulated until 1998 and 2001 respectively; that is, during the approximate years that Rushdie's archive was transferred to Emory.

The uniting of a critical energy that is now shared among textual scholars, book historians, and literary archives, and, which remains focused on a common interest in the inherent subjectivities of the production and reproduction of ideas, emerged during the mid 1990s with scholars like Johns and Kastan leading the way.

To-date, however, this shared critical space has focused on the interrogation of the text, broadly conceived as a finished product ready to be sold and circulated. Currently, scholars like Kirschenbaum are pushing the boundaries of textual scholarship to include concern for the more general gestation of texts; but with a keen interest in how their specific cultivation is inextricably linked to evolving digital technologies. It is an opening up of a new form of critical discourse made possible by the work of institutions like Emory University and the Harry Ransom Center and which are rooted in, in Kirschenbaum's words, "the forensic imagination." Here too, however, we find more points of critical synergy than distinction.

\footnotetext{
$26 \quad \operatorname{Kastan}(2001) 136$.

27 Johns (1998) 30.

28 Johns (1998) 8.
} 


\section{Into the Twenty-first Century}

"We live in a time of forensic imagination," Matthew Kirschenbaum writes in Mechanisms: New Media and the Forensic Imagination:

as evidenced by the current vogue for forensic science in television drama and genre fiction. Forensics in this popular sense returns us to the scene of the crime; as a legal and scientific enterprise forensic investigation has its origins in the same nineteenth-century era that produced the great inscribing engines of modernity - the gramophone, film, and the typewriter all among them. ${ }^{29}$

For the scholar of contemporary literature, the "scene of the crime" is the interactive space between author and computer that shapes the formation of texts in a digital age. It follows that curators like Farr are justifiably excited about the opportunity for digital media to both retain and, in some way, recreate the authors' process of composition within the precise technological space that shaped their artistry.

Medieval scholars, however, have long stressed that the close study of the context of creation initiates points of entry into the interrogation of a manuscript's intellectual content. This is, of course, common to a field that has a long history of decoding and interpreting palimpsests which, to the eyes of modern scholars present a textual nightmare.

The intrigue of this critical unity does not, however, simply jump from medieval contexts and reappear in post-modern digital criticism. Rather, it increasingly runs through the interrogation of texts across centuries of distinct technological innovations. And, while scholars like Kastan and Johns have lead the charge into the revaluation of early modern texts, it is the work of scholars like Lawrence Rainey who urged scholars of more contemporary literature to question their assumptions about the very nature of archival materials that had long assumed to have exhausted their research value and were increasingly looked upon as museum objects.

"If we are to restore the specificity of the prepublication materials and assess their bearing on critical understandings of The Waste Land," Lawrence Rainey writes in Revisiting The Waste Land, "we must first return to the manuscripts themselves, revisiting the debates which ground to a halt in the mid1980s."30 Rainey's preference to "return to the manuscripts" of the twentieth

29 Kirschenbaum (2008) 250.

$30 \quad$ Rainey (2006) 2. 
century poem that has received arguably the most intense critical attention, highlights this resurgence of critical interests among scholars of the twentieth century regarding the primacy or at least critical parity of historiography and concern for the technical manufacture of texts with their intellectual and creative content.

The Waste Land manuscripts have, of course, been the source of focused scholarly attention since their donation to the Berg Collection of British and American Literature in 1968. Harcourt published The Facsimile Edition in 1971. Across the past half-century these manuscripts have not changed in their intellectual content or physical composition. This may seem laughably obvious. Amid a set of critical discourses that gave priority to literary theory and close reading, however, these manuscripts and typescripts remained in a state of critical dormancy. Rainey simply asked of these manuscripts fresh questions that were philological in their orientation but specific in their concern for a forensic investigation, and which elicited fresh answers that provided for a "new" and historically determinative appreciation for Eliot's creative process. In terms of establishing a critical perspective based on a continuum of philological interests, Rainey showed with cunning insight that the eventualities of the poem's composition, its problematic migration from manuscript to typescript, and its manufacture as a printed object outlines a succession of multifarious matrices replete with their own contingencies and which collectively illustrate the inherent subjectivities of the "text."

"The specificity of the prepublication materials," writes Rainey, "- their heft, their material and historical density - has been levelled by a process of abstraction into 'text,' or even 'the 1921 text,' that definite article urging a monolithic entity that is at odds with the experience of pondering the undated, disordered scraps that jostle one another in the facsimile edition."31 Rainey's observations, made from the distance of successive centuries, echo the kinds of philological concern for the medieval manuscript articulated by scholars such as Nichols, Wenzel and Auerbach, and, contemporary concerns for the printed book offered by Johns and Kastan.

By "pondering" Rainey portends an incisive study of Eliot's manuscripts that combines philological discourse with a close study of their materiality which might best be described as "forensic" in its orientation. "We must establish a chronology for the entire corpus of prepublication materials to furnish a coherent account of the poem's production, assaying its significance for longstanding debates about the plan or program which shaped the poem's composition." Rainey continues,

$31 \quad$ Rainey (2006) 2. 
... we need to integrate those considerations into a history specific to the early twentieth century, a culture of the book that gravitated around the epitome of modern communication flows, the typewriter, and that recognizably modern protagonist, the typist. "Such an exercise needs no apology," wrote Hugh Kenner at the outset of his own attempt to address the prepublication manuscripts some thirty years ago. "The Waste Land is still a determinate of modernist consciousness, post-modernist also if it has come to that, and the profit ... may be that we shall learn a little more about the history of our own minds." Or, as Ezra Pound put it in his preface to the facsimile, "The more we know of Eliot, the better." 32

What Rainey discovers remains, from the point of view of traditional philology, strikingly obvious.

The key to unlocking the precise chronology of The Waste Land's composition is revealed during a historically sensitive review of the technology of its production (primarily typewriters) and in the very fabric of the allied technologies (primarily paper) used during the poem's composition. "These typewriters," observes Rainey, "produced characters generally rather similar in appearance."

Yet on closer scrutiny they can be distinguished from each other by several features. One is the minuscule forms of the letters $t$ and $f$. In the typewriter used for parts I and II the descender of the lower-case $t$ ends with a finishing stroke that seems oddly constricted, curving back sharply as it raises toward the cross-stroke above. Similarly, the ascender of the lowercase $f$ concludes with an arc that curls back toward the character's body, giving it a crabbed appearance, and it ends at a point high above the level of the cross-stroke. ${ }^{33}$

"Eliot was a frugal man," Rainey further observes, "at least in the years 1914 1922." Amazingly, it is in fact Eliot's parsimonious habits that provide the key evidence used to unravel The Waste Land's precise pre-publication history.

"Despite earning a relatively substantial salary at Lloyds Bank from 1917 onward," Rainey continues, "he was beset by worries over money, prompted chiefly by Vivien's many medical expenses and the need to keep a cottage in the country where she spent much of her time. His frugality extended to his consumption of paper as well: he seems to have purchased relatively small batches

$32 \quad$ Rainey (2006) 2.

33 Rainey (2006) 34 . 
of paper that would last at most a few months, often only a few weeks, before he would purchase another. As a consequence, his letters can serve as a control base for establishing the dates of the prepublication materials of The Waste Land." ${ }^{44}$ Eliot's preference for particular paper stock proves determinative. "Eliot," notes Rainey, "began to use Hieratic Bond paper in his correspondence in the first letters that he wrote after his return from Margate to London. Quite plainly, the paper was part of a small supply which he had purchased while in Margate, the remainder of which he then proceeded to use up while in London. The Hieratic Bond passages, then, were all composed while Eliot was in Margate." 35

Once Rainey discerns from within these distinct paper stocks a latent historical narrative establishing a precise chronology of Eliot's creative process is easily achieved. "Given the preponderance of letters on British Bond which date from the period 9-22 May, as well as the London Letter, May 1921, which must have been posted by 1 May or thereabouts, it seems safe to say that the typescripts of Parts I and II were produced during this period, and that they represented a summation of work that had been in progress since March or February, perhaps even the last week of January." 36

Rainey's study offers, arguably, the most determinative contribution to contemporary understandings of both Eliot and The Waste Land to appear across the past several decades or, arguably, since the poem's publication in 1921. Rainey's insights provide a determinative chronology and perspective on the prepublication history of the poem, that is, a precise critical gesture that helps to recover the various contexts of the poems creation.

Most succinctly, Rainey subjects a modern poem (perhaps, the modern poem) to a set of critical subjectivities that recall philological concerns for the complexities of the "manuscript matrix." His criticism epitomizes the recent awakening of scholars to a particularly, and largely philological, concern for literary matrices across a breadth of technological mediations.

Moreover, Rainey's particular investigation represents, from a technological point of view, a kind of middle ground in his specific concern for the influence of the typewriter on the formation of the literary imagination. The impress on the typewriter on the formation of new literary matrices can trace it roots back to Mark Twain's revolutionary decision to produce a typescript of Life on the Mississippi (well-regarded as the first literary typescript produced by an American author) and claims an experimental apex with Jack Kerouac's famous

\footnotetext{
34 Ibid.

35 Rainey (2006) 11.

36 Rainey (2006) 19 .
} 
experiment involving a 120 foot scroll, a typewriter, and his journey across the United States (On The Road, of course, the resulting text). ${ }^{37}$

In 2011, John McMillan published, Smoking Typewriters: The Sixties Underground Press and the Rise of Alternative Media in America. McMillan's study, like that of Rainey, advances philological discourses deep into the twentieth century. "We have no shortage of books seeking to explain how so many American youths grew restless and dissatisfied with their country in the early $1960 \mathrm{~s}$ and why they became so intensely radical in the mid-196os," Rainey observes. “The New Left's development, however, can't be accounted for by these [Civil Rights, Vietnam, etc.] factors alone; it has also been necessary for scholars to examine the internal dynamics that propelled the movement." 38 Such investigation leads, for McMillan, directly into specific interpretation of the contexts of composition and dissemination of radical newspapers. "By showing how underground newspapers educated, politicized, and built communities among disaffected youths in every region of the country this book contributes," McMillan argues, "to a broader revisionist effort." 39

While McMillan's interests may be more broadly socio-historical, they bare the unmistakable impress, I would argue, of the work of Rainey (as well as Johns, Kastan, and Moretti) in their indebtedness to New Philology as it was imagined by scholars during the late 1980 s and early 1990 .

\section{Old Challenges Reimagined}

Writing at the beginning of the 1990s Siegfried Wenzel observed with caution that, "there are, however, several pertinent objections that might be raised to the claim that philology continues to have an important heuristic value." Among these concerns, Wenzel notes, is the argument that Philology, "was done, and perhaps done well, in the nineteenth century and early twentieth centuries; but - quite apart from the fact that our modern intellectual quest has moved on beyond the typical concerns of philology - the major insights which philology could furnish have been furnished, and nothing new can be added." Or, as Wenzel continues, there is a criticism that "philology is no longer relevant to the main objective of literary studies," and, less tenable still, that

\footnotetext{
37 Mark Twain was especially fascinated by the prospect of mechanical typesetting. During the 1870 s Twain in fact went bankrupt financing James Paige's Paige Compositor: an early competitor of Ottmar Mergenthaler's Lintotype Machine.

$38 \quad$ McMillan (2011) 5 .

39 McMillan (2011) 6.
} 
philologists work, "in blissful ignorance of such notions as structuralism, the hermeneutic circle, or indeterminacy."40

The timing of Wenzel's authorship is important. Working with the critical environment of the late 1980s and early 1990s his observations were in fact keen in the appreciation for the technologies of literary composition. At the time, such concerns were simply dismissed as irrelevant to classicists and medievalists and had little to contribute to the interpretation of texts authored and "published" since Gutenberg. Things, however, were about to change.

By 1990, it is without question that the computer had been made "personal" (really the defining feature of the current digital revolution) but scholarly concern for its impress on the shapes of intellectual and literary history remained, at best, nascent. By the mid-199os scholars like George Bornstein in works including, The Iconic Page in Manuscript, Print, and Digital Culture (1998) and Material Modernism: The Politics of the Page (2006), were beginning to ask certain fundamental questions about the nature of literary production within twentieth century contexts. "If the Mona Lisa is in Paris, at the Louvre," Bornstein wonders in his introduction, "where is King Lear?"41

As I have been describing, scholars of the history of the book in particular picked-up on this point of critical revision. What scholars like Adrian Johns and David Kastan have shown, and shown with remarkable sensitivity, is that the "book," especially when examined from an artifactual point of view, is simply a piece of highly commodified technology that from the 145 os onward fundamentally reshaped how scholars and intellectuals have developed and communicated ideas. ${ }^{42}$

Working within this critical perspective, what in fact the digital revolution has impressed upon a growing contingent of scholars is that authorship has always combined subjectivities of technology and historiography. While this may present as a commonplace critical observation, the fact remains that such philological engagement with texts has, to-date, largely remained the almost

\footnotetext{
$40 \quad$ Wenzel (1990) 13.

41 Bornstein (1993) 5 .

42 I feel it is important to note the early contribution of Elizabeth Eisenstein and her publication of The Printing Press as an Agent of Social Change (1980). While more contemporary scholars (including Johns) have established their particular analysis of the subjectivities of the printing press in opposition to, what is sometimes referred to as, Eisenstein's "magisterial" regard for Gutenberg's workshop, I think it important to appreciate Eisenstein as beginning a critical discourse that was, at the time of her authorship, largely absent from academic circles. Further, I think it fair to consider that Eisenstein was making a very challenging (and laudable) foray into what has long been a kind of "boys club" of the Rare Book world.
} 
exclusive domain of classical and medieval scholars. The opening of the Salman Rushdie archive illustrates that such defined interests are giving way to much broader and more inclusive critical exchanges.

In her recent New York Times article entitled, The Muses of Insert, Delete and Execute, Schuessler quotes Kirschenbaum as stating that, "The story of writing in the digital age is every bit as messy as the ink-stained rags that would have littered Gutenberg's print shop or the hot molten lead of the Linotype machine... Pay no attention to the neatly formatted and deceptively typo-free surfaces of the average Microsoft Word file." 43 Kirschenbaum made these comments, as Schuessler points out, at a recent lunchtime lecture at the New York Public Library titled "Stephen King's Wang," "a cheeky reference to that best-selling novelist's first computer, bought in the early 1980s." 44 Kirschenbaum's observations advance upon the critical insights of scholars like Johns and Kastan: "The truth is that all of the technologies of writing betray 'real presence'; always they offer a simulacrum of a voice that is by definition absent," Kastan observes. "The preference then of one over another cannot be based on its presumption of its greater authenticity. And even the pencil, it is worth reminding ourselves, is no more a natural writing tool than the computer. It is just a lot easier to understand how it works and its traces are more directly linked back to their author; that is, they are dependent less upon other agencies than print or digital display, but not therefore any less mediations of the authors work." 45

Kastan's point, of course, is that the very technology of the word processor (like that of the pencil and the printing press) were specifically designed to facilitate the production of a single manuscript that conceals through its very process of composition the errors, emendations, and edits associated with material (paper) based technologies. Reflecting on evidences discovered within his own archive, Salman Rushdie himself comments on the writers' fetish for the "clean" page. "Like many writers I don't like to show people pages with many x-ings out," Rushdie explained during an interview with Erika Farr. "I found," Rushdie continued, "that because of the ease of revision, because of the ease of cleaning up the page ... [it] left more time available for the actual work. That you actually revised more just because you could ... The fact that you could endlessly improve made me more willing to do that. It was, in the

43 Kirschenbaum in Schuessler, Jennifer, "The Muses of Insert, Delete and Execute," in New York Times December 26, 2011.

44 Kirschenbaum in Schuessler, Jennifer, "The Muses of Insert, Delete and Execute," in New York Times December 26, 2011.

$45 \quad \operatorname{Kastan}(2001) 135$. 
end, actually beneficial to the finished product. I would go over it five or six times more than I would on a typed page."46

While from Rushdie's point of view the word processor may have simply replaced the role of the pencil, the typewriter, and, the printer in creating a literary product that is appreciably clean and therefore trustworthy, from a philological perspective, and, more certainly from that of the archive, such concern for the concealment of process presents a tremendous complexity of challenges. In short, while present scholarship continues to engage with a broadening of assumptions about intellectual and literary history that medievalists have long appreciated ("medieval writing does not produce variants; it is variance") the current technologies that facilitate literary production are simultaneously concealing its process in ways which make the Archimedes Palimpsest appear almost transparent.

It is therefore worth considering the evolution of what might be imagined to be the contemporary scriptoria or print shop. Here again Philology, and New Philology specifically, offers points of entry into the poignancy of technological and historical context. In turn, however, New Philology also stands to advance its own critical understandings by considering closely the strategies of contemporary archivists and literary scholars to capture a revolutionary breadth of evidences, and which allow for scholars' close study of authorship (and literature generally) as it entered and now progresses though our age of the digital incunabula.

\section{Digital Incunabula: Contexts of Creation}

On April 1, 1976, Steve Jobs, Steve Wozniak and Ronald Wayne established Apple Computer. Eight months later the company was formally incorporated on January 3, 1977. Apple's first product, the Apple I Personal Computer Kit (hand built by Wozniak) was introduced at the Homebrew Computer Club and retailed for $\$ 666.66$.

Apple's origins are humble. Indeed they reflect the combination of entrepreneurship, anti-intellectual experimentation, and insightful comprehension of historical and technical demands that combine to reveal (to a few minds each century) the potential for lucrative re-invention of the process by which we compose and share ideas. Certainly Jobs, Wozniak and Wayne deserve to be

46 Salman Rushdie interview with Erika Farr (Director of Born Digital Archives at Emory). As of September 28, 2012 video available at http://www.youtube.com/watch?v=kmbio QcRmkM. 
considered along with influences of Gutenberg, Fourdrinier, and Mergenthaler.

For the purposes at hand, it is essential to appreciate that Apple's evolution is of interest for the precise reason that at no other moment in history since Gutenberg has an individual or group of individuals brought into alignment a particular focus of genius with the expectations of a culture that was ready to accept and embrace new processes of creating ideas and transmitting them across time and space. The result of Apple's success is nothing less than Gutenberg-esque in terms of its determinative influence on language, its production, its continued self-invention, and in the processes by which individual imaginations pursue creative processes.

To chart a line of evolution from Apple's origins in a garage in Palo Alto, California during the mid-1970s to the announcement by the Rare Books and Manuscripts Division at Emory University that they had made available for scholarly research the Salman Rushdie Archive is to realize a historical period of less than forty years. Considered within the more general expanse of recorded intellectual history this is a shockingly brief period of time. In short: we live in a world of the digital incunabula.

On November 19, 2007, Amazon released the First Generation Kindle. The device retailed for $\$ 399$.oo. In less than six hours Amazon sold its entire reserve. The Kindle remained out of stock until late April. The Kindle 2 was released on February 23, 2009. To promote the new Kindle, author Stephen King made his (then) new novella's UR available exclusively through Amazon.

The genius behind the Kindle's success is easily explained, and has undeniable precedent in Gutenberg's successful commodification of print during the middle of the fifteenth century. Quite simply, from the point of view of product development, Amazon privileged "e-ink technology" over enhanced operability. E-ink uses electronic impulses to display and re-display actual ink across the screen. There is no backlight. The result is a digital depiction of printed text that remains ink based and which represents a kind of seamless continuum of representing ideas by means of an ink-based delineation. The result, from a reader's perspective, is a replication of a familiar textual space. One that in fact presents the reader, who remains, of course, a consumer, with a confidence in the product that is based on its faithful representation of a printed page.

Amazon's development of the Kindle was both prescient, and strikingly consistent with technical decisions that Gutenberg made during the middle of the fifteenth century and which resulted in his careful development of a technology that mimics to an astonishing degree its manuscript antecedents. Several centuries later, the typewriter was designed to replicate the appearance of printed texts. More currently, the entire architecture and 
nomenclature of word-processing programs have been carefully designed to represent the "familiar" to a generation of users who have had to be convinced (as consumers) to embrace a new technology. The same holds true for E-Readers. The list goes on and on. Print culture remains, and has always been, beholden to consumer interests that remain decidedly conservative and resistant to radical change. After all, "Early modern printing was not joined by any obvious or necessary bond to enhanced reliability and truth. That bond had to be forged."

In his introduction to New Philology Nichols writes that, "The manuscript folio contains different systems of representation: poetic or narrative text, the highly individual and distinctive scribal hand(s) that inscribe the text, illuminated images, colored rubrications, and not infrequently glosses or commentaries in the margins or interpolated in the text. Each system is a unit independent of others and yet calls attention to them; each tries to convey something about the other while to some extent substituting for it." 47

If scholars generally are to take seriously, and they most certainly should, Nichols' observations, then they must consider that if the garage in Palo Alto (which still stands) where Apple traces its origins is not a scriptoria or print shop in and of itself, it is certainly the most immediate context of creation that explains the work of twentyfirst century scribes and printers. It is within that garage that the "personal" dimension of the computer was realized. This realization brought into the singular control of the author the multifarious functions of the scribe and master printer and has changed forever the process of literary production, and, its process of remembrance and interpretation.

\section{Conclusion}

The Salman Rushdie Archive offers the opportunity to revaluate how established philological interpretations of classical and medieval texts are currently being re-imagined and applied to the investigation of texts dating from the early modern period. In fact these (re)imaginings have been shown to offer important points of scholarly entry into the interpretation of contemporary texts which often combine the contingencies of manuscript production (broadly conceived), with the commensurate vicissitudes of mechanical printing technologies including the printing press, the typewriter, the Linotype etc., and now with an increasing reliance (in philological terms) upon complex digital matrices.

$47 \quad$ Nichols (1990) 7 . 
Indeed, critical observations made by scholars like Nichols (dating from the early 1990s) are now appreciated as representing a more inclusive discourse.

What is "new" in our enterprise might better be called "renewal," renovatio in the twelfth-century sense. On the one hand, it is a desire to return to the medieval origins of philology, to its roots in a manuscript and culture where, as Bernard Cerquiglini remarks, "medieval writing does not produce variants, it is variance." On the other hand, a rethinking of philology should seek to minimize the isolation between medieval studies and other contemporary movements in cognitive methodologies, such as linguistics, anthropology, modern history, cultural studies, and so on, by reminding us that philology was once among the most theoretically avant-garde disciplines. ${ }^{48}$

After all, as Frederick Nietzsche observes, "our writing tools are also working on our thoughts." 49

\section{Works Cited}

Bornstein, G., Material Modernism: The Politics of the Page (New York, 2001).

Busby, K., ed., Towards a Synthesis: Essays on New Philology (Amsterdam, 1993).

Cerquiglini, B., Éloge de la variante: Histoire critique de la philologie (Paris, 1989).

Colli, G. and M. Montinari, eds., F. Nietzsche Briefwechsel: Kritische Gesamtausgabe (Berlin, 1975).

Johns, A., The Nature of the Book (Chicago, 1998).

Kastan, D., Shakespeare and the Book (New York, 2001).

Kirschenbaum, M.G., Mechanisms:New Media and the Forensic Imagination (Cambridge, MA, 2008).

McMillan, J., Smoking Typewriters (New York, 2011).

Reviel, N. and W. Noel, eds., The Archimedes Codex: How a Medieval Prayer Book is Revealing the True Genius of Antiquity's Greatest Scientist (Philadelphia, 2007).

Nichols, S.G., "Introduction: Philology in a Manuscript Culture," in Speculum 65 (1990), pp. 1-10.

Rainey, L., Revisiting The Waste Land (New Haven, 2005).

Wenzel, S., "Reflections on (New) Philology," in Speculum 65 (1990), pp. 11-18.

48 Nichols (1990) 1.

49 Nietzsche in Colli and Montinari (1975) 84. 
PART 2

Narrativity

$\because$ 